Bài báo khoa học

\title{
Hiện trạng phát thải khí nhà kính tại Việt Nam: Cơ hội và thách thức
}

\author{
Nguyễn Văn Hiếu ${ }^{*}$, Nguyễn Hoàng Nam² \\ ${ }^{1}$ Trung tâm Phát triển nguồn nhân lực Tài nguyên và Môi trường $(\mathrm{CEN})$; \\ hieunguyen@cen.org.vn; \\ ${ }^{2}$ Viện chiến lược chính sách Tài nguyên và Môi trường (ISPONRE); \\ nguyenhoangnam275@gmail.com; \\ *Tác giả liên hệ: hieunguyen@cen.org.vn; Tel.: +84-901828895
}

Ban Biên tập nhận bài: 18/5/2021; Ngày phản biện xong: 14/6/2021; Ngày đăng bài: $25 / 8 / 2021$

Tóm tắt: Bài viết này phân tích về phát thải KNK của Việt Nam trong giai đoạn 2000-2030, đặc biệt là các biến động trong 05 lĩnh vực chính gồm: năng lượng; nông nghiệp; các quá trình công nghiệp; chất thải; và sử dụng đất, thay đổi sử dụng đất và lâm nghiệp. Từ đó, những cơ hội và thách thức trong giảm phát thải KNK đã được chỉ rõ. Tiêu biểu, nước ta đang có lợi thế với nhiều biện pháp "không hối tiếc" (no-regret), với chi phí giảm phát thải âm nhưng tổng tiềm năng giảm phát thải lên tới $4,9 \%$, tức hơn một nửa so với mức cam kết $9 \%$ theo NDC cập nhật, trong khi nhu cầu tài chính ứng trước là 3,9 tỷ USD cho giai đoạn 2021-2030. Bài viết cũng phân tích 05 thách thức nổi bật nhất hiện nay, đặc biệt nhấn mạnh 02 thách thức về (i) Thiếu các kế hoạch, hướng dẫn cụ thể để thực hiện giảm phát thải KNK theo NDC ở cấp địa phương và (ii) Thiếu cơ chế, chính sách đủ hấp dẫn để thu hút sự tham gia của khu vực tư nhân. Từ những phân tích đó, bài viết đã đề xuất các vấn đề Việt Nam cần tập trung trong thời gian tới.

Từ khóa: Phát thải khí nhà kính; Giảm nhẹ; Cơ hội; Thách thức.

\section{1. Đặt vấn đề}

Năm 2015, tại Hội nghị lần thứ 21 của các bên tham gia Hội nghị Công ước khung của Liên hợp quốc về biến đổi khí hậu (COP 21), 175 quốc gia và vùng lãnh thổ đã ký thoả thuận Paris với mục tiêu giữ cho nhiệt độ trung bình toàn cầu vào cuối thế kỷ tăng dưới $2^{\circ} \mathrm{C}$ so với thời kỳ tiền công nghiệp, nỗ lực để hạn chế mức tăng ở dưới $1,5^{\circ} \mathrm{C}$ và đạt được cân bằng giữa phát thải và hấp thụ khí nhà kính $(\mathrm{KNK})$ (phát thải bằng 0 ) vào nửa cuối thế kỷ này [1]. Hầu hết các nước ký kết đã đệ trình Đóng góp quốc gia tự quyết định (Nationally Determined Contributions $-N D C$ ) bản thứ nhất của mình tới Ban thư ký Công ước khung của Liên Hiệp Quốc về Biến đổi khí hậu (UNFCCC) vào năm 2016. Năm 2020, bản sửa đổi lần cuối của các quốc gia sẽ được trình lên Ban thư ký UNFCCC [2]. Đây là thoả thuận toàn cầu đầu tiên ràng buộc trách nhiệm pháp lý đối với tất cả các bên về giảm phát thải KNK, ứng phó với biến đồi khí hậu $(\mathrm{BĐKH)}$ để phát triển bền vững.

Mặc dù Việt Nam chỉ đóng góp tỷ lệ thấp lượng phát thải KNK toàn cầu và là quốc gia không thuộc Phụ lục 1 của UNFCCC (nhóm các nước phát triển với lượng phát KNK lớn, chịu ràng buộc bởi các cam kết cụ thể về cắt giảm phát thải KNK theo Nghị định thư Kyoto 1997), Việt Nam vẫn thể hiện sự cam kết mạnh mẽ việc giảm phát thải KNK thông qua việc chủ động cùng các nước trên thế giới cam kết và thực hiện các hiệp ước, thỏa thuận quốc tế về $\mathrm{BĐKH}$, trong đó có Thỏa thuận Paris này. Theo đó, Việt Nam đã gửi Ban thư ký UNFCCC 
tại Hội nghị COP21 Dự kiến đóng góp quốc gia tự quyết định INDC (INDC-Intended Nationally Determined Contributions) vào năm 2015. Việt Nam thể hiện cam kết cắt giảm phát thải của mình tới năm 2030 thông qua các mục tiêu tự cắt giảm $8 \%$ so với kịch bản phát thải thông thường (BAU) quốc gia và lên tới $25 \%$ với sự hỗ trợ quốc tế [3]. Với việc tham gia Thỏa thuận Paris và ban hành Kế hoạch thực hiện Thỏa thuận Paris về BĐKH (Quyết định số 2053/QĐ-TTg ngày 28/10/2016 của Thủ tướng Chính phủ) [4], INDC của Việt Nam đã chính thức trở thành Đóng góp do quốc gia tự quyết định (NDC).

Ngày 24/7/2020, Thủ tướng Chính phủ đã thông qua nội dung NDC cập nhật của Việt Nam cho UNFCCC tại văn bản số 1982/VPCP-QHQT. Theo đó, NDC cập nhật của Việt Nam xác định bằng nguồn lực trong nước, đến năm 2030 Việt Nam sẽ giảm $9 \%$ tổng lượng phát thải KNK so với kịch bản BAU và có thể tăng đóng góp lên tới $27 \%$ khi nhận được hỗ trợ quốc tế thông qua hợp tác song phương, đa phương và thực hiện các cơ chế mới theo Thỏa thuận Paris về BĐKH [5].

Bài viết này được thực hiện với mục tiêu nhằm đánh giá thực trạng và dự báo về phát thải KNK của Việt Nam, đồng thời làm nổi bật các cơ hội và thách thức mà Việt Nam cần vượt qua để đạt được mục tiêu giảm phát thải KNK đã đề ra.

\section{Phương pháp nghiên cứu}

Nghiên cứu này đánh giá thực trạng và xu hướng phát thải KNK tại Việt Nam trong giai đoạn 2000-2030 đối với 05 lĩnh vực, gồm: năng lượng; nông nghiệp; sử dụng đất, thay đồi sử dụng đất và lâm nghiệp (LULUCF); chất thải; các quá trình công nghiệp (IP). Khung đánh giá được trình bày tại Hình 1 .

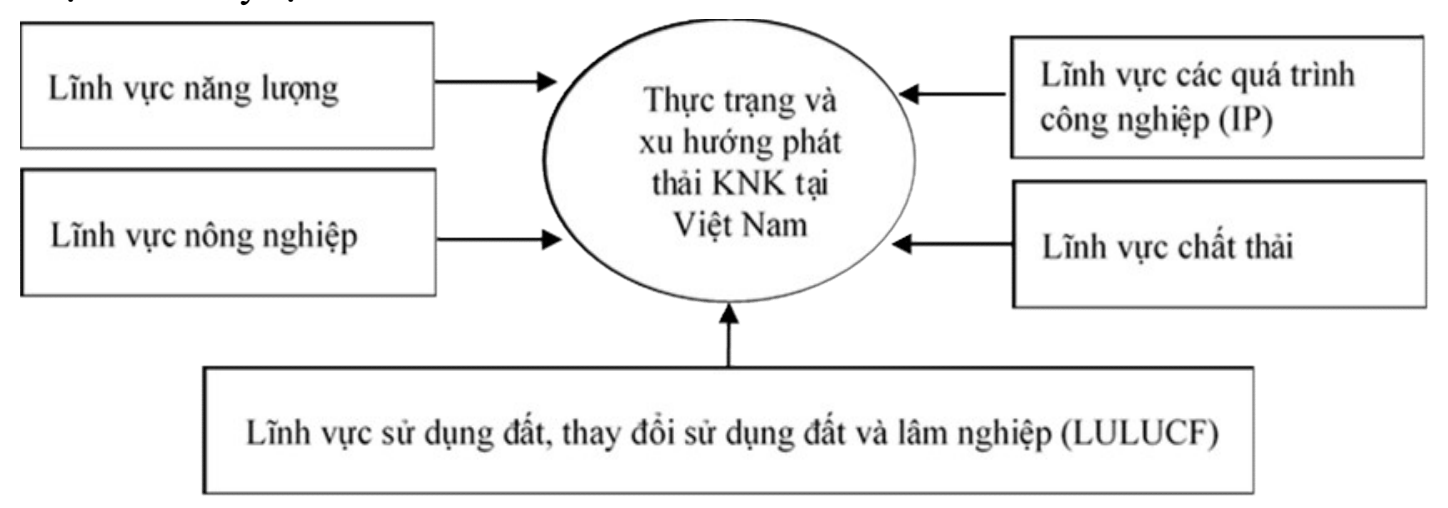

Hình 1. Khung đánh giá thực trạng và xu hướng phát thải KNK tại Việt Nam.

Số liệu về thực trạng và dự báo phát thải KNK của Việt Nam cùng với 07 quốc gia so sánh (gồm Mỹ, Hàn Quốc, Nhật Bản, Trung Quốc, Ấn Độ, Braxin và Thái Lan) được tổng hợp từ nguồn là báo cáo chính thức (đặc biệt là NDC) do các quốc gia gửi tới UNFCCC [6]. Việc lựa chọn các quốc gia so sánh dựa trên cơ sở đa dạng hóa trình độ phát triển kinh tế (03 quốc gia thuộc nhóm nước phát triển và 04 quốc gia thuộc nhóm nước đang phát triển). Đây cũng là những nước xếp hạng cao về tổng lượng phát thải KNK trên thế giới. Đặc biệt, Thái Lan là quốc gia láng giềng trong khu vực Đông Nam Á, có nhiều đặc điểm chung với Việt Nam.

Riêng đối với số liệu về tổng phát thải KNK toàn cầu, do UNFCCC còn thiếu số liệu báo cáo của nhiều nước, nên nghiên cứu này sử dụng số liệu tổng toàn cầu được trích xuất từ công cụ Climate Analysis Indicators Tool (CAIT) của Climate Watch [7]. Tuy nguồn số liệu này không có tính chính thức bằng số liệu từ báo cáo của các quốc gia gửi tới UNFCCC, nhưng cũng rất tin cậy và đã được nhiều nghiên cứu sử dụng [8-10], đặc biệt trong trường hợp thiếu thông tin từ UNFCCC.

Về chuỗi thời gian có số liệu kiểm kê, Việt Nam đã thực hiện kiểm kê KNK vào các năm 1994, 2000, 2010, 2013, 2014. Dựa trên mức độ sẵn có về số liệu phát thải KNK của Việt 
Nam và các quốc gia so sánh, nghiên cứu sử dụng kết quả kiểm kê của Việt Nam vào các năm 2000, 2010, 2014 để tiến hành phân tích và đánh giá. Ngoài ra, trong 7 quốc gia so sánh đối chứng, dữ liệu về phát thải KNK của Trung Quốc năm 2000 bị khuyết do Trung Quốc thực hiện kiểm kê KNK vào các năm 1994, 2005, 2012, 2014. Do đó, số liệu về phát thải KNK của Trung Quốc năm 2000 được nội suy dựa trên số liệu phát thải KNK các năm sẵn có.

\section{Kết quả nghiên cứu và thảo luận}

\subsection{Phát thải KNK tại Việt Nam giai đoạn 2000-2014}

Trong giai đoạn 2000-2014, lượng phát thải KNK của Việt Nam tăng từ 150,90 triệu tấn $\mathrm{CO}_{2}$ tđ lên 283,97 triệu tấn $\mathrm{CO}_{2}$ tđ̛ (tăng 1,88 lần). Mốc 2014 được chọn do đây là năm Việt Nam thực hiện kiểm kê khí nhà kính và có số liệu thực tế ở quy mô quốc gia. Xét theo lĩnh vực, phát thải từ lĩnh vực nông nghiệp và năng lượng chiếm tỷ lệ lớn nhất, lần lượt chiếm $60,4 \%$ và $31,6 \%$ tổng phát thải KNK quốc gia năm 2014 . Trên bình diện toàn cầu, phát thải KNK của Việt Nam chiếm $0,4 \%$ (năm 2000) và tăng lên $0,7 \%$ (năm 2014) (Bảng 1).

Bảng 1. Phát thải KNK tại Việt Nam trong giai đoạn 2000-2014 [11-13].

\begin{tabular}{|c|c|c|c|c|c|c|c|c|c|}
\hline \multirow[b]{3}{*}{ Lĩnh vực } & \multicolumn{3}{|c|}{ Năm 2000} & \multicolumn{3}{|c|}{ Năm 2010} & \multicolumn{3}{|c|}{ Năm 2014} \\
\hline & Việt I & am & \multirow[b]{2}{*}{$\begin{array}{c}\text { Tỷ lệ so } \\
\text { với thế } \\
\text { giới }\end{array}$} & \multicolumn{2}{|c|}{ Việt Nam } & \multirow[b]{2}{*}{$\begin{array}{c}\text { Tỷ lệ so } \\
\text { với thế } \\
\text { giới }\end{array}$} & \multicolumn{2}{|c|}{ Việt Nam } & \multirow[b]{2}{*}{$\begin{array}{c}\text { Tỷ lệ so } \\
\text { với thế } \\
\text { giới }\end{array}$} \\
\hline & $\begin{array}{c}\text { Lượng } \\
\text { KNK } \\
\text { phát thải }\end{array}$ & Tỷ lệ & & $\begin{array}{c}\text { Lượng } \\
\text { KNK } \\
\text { phát thải }\end{array}$ & Tỷ lệ & & $\begin{array}{c}\text { Lượng } \\
\text { KNK } \\
\text { phát thải }\end{array}$ & Tỷ lệ & \\
\hline Năng lượng & 52,77 & $38,9 \%$ & $0,20 \%$ & 141,10 & $53,0 \%$ & $0,41 \%$ & 171,62 & $53,4 \%$ & $0,48 \%$ \\
\hline IP & 10,01 & $7,4 \%$ & $0,72 \%$ & 21,20 & $8,0 \%$ & $0,95 \%$ & 38,62 & $12,0 \%$ & $1,45 \%$ \\
\hline Nông nghiệp & 65,09 & $47,9 \%$ & $1,28 \%$ & 88,30 & $33,2 \%$ & $1,60 \%$ & 89,75 & $27,9 \%$ & $1,58 \%$ \\
\hline LULUCF & 15,10 & - & $0,90 \%$ & $-19,20$ & - & - & $-37,54$ & - & - \\
\hline Chất thải & 7,93 & $5,8 \%$ & $0,54 \%$ & 15,40 & $5,8 \%$ & $1,05 \%$ & 21,51 & $6,7 \%$ & $1,40 \%$ \\
\hline Tổng* & 135,80 & $100 \%$ & $0,40 \%$ & 266,00 & $100 \%$ & $0,61 \%$ & 321,51 & $100 \%$ & $0,70 \%$ \\
\hline Tổng** & 150,90 & & $0,42 \%$ & 246,80 & & $0,55 \%$ & 283,97 & & $0,61 \%$ \\
\hline
\end{tabular}

Ghi chú: Đon vị luợng phát thải KNK là triệu tấn $\mathrm{CO}_{2}$ tđ; * Tổng luợng phát thải không bao gồm LULUCF; ** Tổng lương phát thải bao gồm LULUCF.

Về cường độ phát thải theo dân số, trong giai đoạn 2000-2014, giá trị này tăng từ 1,89 tấn $\mathrm{CO}_{2}$ tđđ/người lên 3,1 tấn $\mathrm{CO}_{2}$ tđđ/người (tăng 1,6 lần). Như vậy, năm 2014, cường độ phát thải theo dân số của Việt Nam bằng một nửa so với trung bình thế giới $(6,43)$ và thấp hơn một số quốc gia so sánh như Braxin $(3,86)$, Trung Quốc $(8,20)$, Nhật Bản $(9,44)$, Hàn Quốc $(12,77)$, Mỹ $(19,18)$, Thái Lan $(3,50)$. Khi xét chi tiết theo các lĩnh vực (Hình $2 a)$, ta thấy một số điểm đáng lưu ý sau:

(i) Lĩnh vực năng lượng, giá trị này có xu hướng tăng trong giai đoạn 2000-2014 (từ 0,66 lên 1,87 tấn $\mathrm{CO}_{2}$ tđđ/người). Năm 2014, cường độ phát thải theo dân số của Việt Nam trong lĩnh vực năng lượng cao hơn so với Ấn Độ $(1,47)$. Tuy nhiên, giá trị này vẫn thấp hơn so với trung bình của thế giới $(4,97)$ và một số quốc gia so sánh như Braxin $(2,26)$, Trung Quốc $(7,01)$, Nhật Bản $(9,48)$, Hàn Quốc $(11,80)$, Mỹ $(17,92)$, Thái Lan $(3,50)$.

(ii) Lĩnh vực nông nghiệp, giá trị này tăng từ 0,81 lên 0,98 tấn $\mathrm{CO}_{2}$ tđđ/người trong giai đoạn 2000-2014. Năm 2014, cường độ phát thải theo dân số của Việt Nam trong lĩnh vực nông nghiệp thấp hơn Mỹ $(1,91)$ nhưng cao hơn trung bình chung của thế giới $(0,78)$ và một 
số quốc gia phát triển như Nhật Bản $(0,00)$, Hàn Quốc $(0,41)$ và đang phát triển như Braxin $(0,10)$, Trung Quốc $(0,61)$, Ân Độ $(0,32)$, Thái Lan $(0,85)$.

(iii) Lĩnh vực IP, trong giai đoạn 2000-2014, giá trị này tăng từ 0,13 lên 0,42 tấn $\mathrm{CO}_{2}$ tđđ/người. Năm 2014, cường độ phát thải theo dân số của Việt Nam trong lĩnh vực IP cao hơn so với trung bình của thế giới $(0,37)$. So sánh với một số quốc gia, giá trị này thấp hơn so Braxin $(0,44)$, Trung Quốc $(1,26)$, Hàn Quốc $(1,10)$, Mỹ $(1,20)$, Thái Lan $(0,45)$ nhưng ngang với Nhật Bản $(0,37)$ và cao hơn Ân Độ $(0,15)$.

(iv) Lĩnh vực chất thải, cường độ phát thải theo dân số tăng gấp hơn hai lần trong giai đoạn 2000-2014 (từ 0,1 lên 0,23 tấn $\mathrm{CO}_{2}$ tđđ/người). Năm 2014, cường độ phát thải theo dân số của Việt Nam trong lĩnh vực chất thải cao hơn mức trung bình thế giới $(0,21)$ và cao hơn Braxin $(0,01)$, Trung Quốc $(0,14)$, Ấn Độ $(0,06)$, Nhật Bản $(0,10)$, Thái Lan $(0,21)$; thấp hơn Hàn Quốc $(0,30)$, Mỹ $(0,43)$.

(v) Lĩnh vực LULUCF, Việt Nam đã chuyển từ quốc gia phát thải năm 2000 sang quốc gia hấp thụ KNK. Năm 2014, cường độ hấp thụ KNK/người của Việt Nam ước tính khoảng 0,41 tấn $\mathrm{CO}_{2} \mathrm{t}$ đđ/người, lượng hấp thụ cao hơn Ẩn Độ $(0,23)$ và trung bình của thế giới (phát thải 0,1 tấn $\mathrm{CO}_{2}$ tđ/người). Tuy nhiên, mức độ hấp thụ vẫn còn thấp hơn so với các quốc gia như Mỹ $(2,27)$, Thái Lan $(1,51)$, Trung Quốc $(0,82)$, Hàn Quốc $(0,84)$, Nhật Bản $(0,51)$.

Về cường độ phát thải trên một đơn vị GDP (phát thải/GDP), giá trị này có xu hướng giảm trong giai đoạn 2000-2014 (từ 4,84 $\mathrm{kg} \mathrm{CO}_{2}$ tđ̃ $/ \mathrm{USD}$ xuống còn 1,53 $\mathrm{kg} \mathrm{CO}_{2}$ tđ̃/USD ). Năm 2014, tỷ lệ này vẫn cao gấp khoảng 2,6 lần trung bình thế giới (Hình 2b). Khi xét chi tiết theo các lĩnh vực, ta thấy một số điểm đáng lưu ý sau:

(i) Lĩnh vực năng lượng có đường độ phát thải cao nhất $\left(0,92 \mathrm{~kg} \mathrm{CO}_{2} \mathrm{t}\right.$ đa $/ \mathrm{USD}$ năm 2014). Cường độ phát thải trên một đơn vị GDP của Việt Nam trong lĩnh vực năng lượng cao gấp 2,03 lần so với trung bình chung của thế giới, 4,9 lần so với Braxin; 3,7 lần so với Nhật Bản; 2,3 lần so với Hàn Quốc; 2,8 lần so với Mỹ; 1,54 lần so với Thái Lan.

(ii) Lĩnh vực nông nghiệp đứng thứ $2(0,48 \mathrm{~kg} \mathrm{CO} 2$ tđ/USD năm 2014). Cường độ phát thải trên một đơn vị GDP của Việt Nam trong lĩnh vực nông nghiệp cao gấp 6,7 lần so với trung bình thế giới và cao hơn Braxin 58 lần, Trung Quốc 6 lần, Ân Độ 2 lần, Nhật Bản 4000 lần, Hàn Quốc 34 lần, Mỹ 14 lần và Thái Lan 3 lần.

(iii) Lĩnh vực IP đứng thứ $3\left(0,21 \mathrm{~kg} \mathrm{CO}_{2}\right.$ tđ/USD năm 2014). Cường độ phát thải trên một đơn vị GDP của Việt Nam trong lĩnh vực IP cao gấp 6 lần so với trung bình thế giới và cao hơn Braxin 6 lần, Trung Quốc 1,3 lần; Ấn Độ 2,1 lần; Nhật Bản $(9,78)$; Hàn Quốc (37,74); Mỹ (21,73); Thái Lan (76,66).

(iv) Lĩnh vực chất thải đứng thứ $4\left(0,116 \mathrm{~kg} \mathrm{CO}_{2}\right.$ tđ/USD năm 2014). Cường độ phát thải trên một đơn vị GDP của Việt Nam trong lĩnh vực chất thải cao hơn khoảng 6 lần so với trung bình của thế giới và cao hơn Braxin $(0,54)$, Trung Quốc $(18,61)$, Ân Độ $(38,25)$, Nhật Bản $(2,59)$, Hàn Quốc $(10,38)$, Mỹ, $(7,74)$, Thái Lan $(35,48)$.

(v) Lĩnh vực LULUCF có cường độ phát thải trên một đơn vị GDP năm 2000 ở mức cao $(0,485 \mathrm{~kg} \mathrm{CO}$ tđđđ/USD), cao gấp 9,7 lần so với trung bình của thế giới. Tuy nhiên, đến năm 2014 , lĩnh vực này trở thành lĩnh vực hấp thụ KNK với mức hấp thụ tương đối cao $(-0,20 \mathrm{~kg}$ $\mathrm{CO}_{2}$ tđ/USD). Tuy nhiên, mức độ hấp thụ vẫn thấp hơn Thái Lan $(-0,26)$, cao hơn Trung Quốc $(-0,11)$, Ân Độ $(-0,15)$, Nhật Bản $(-0,01)$, Hàn Quốc $(-0,03)$, Mỹ $(-0,04)$. 


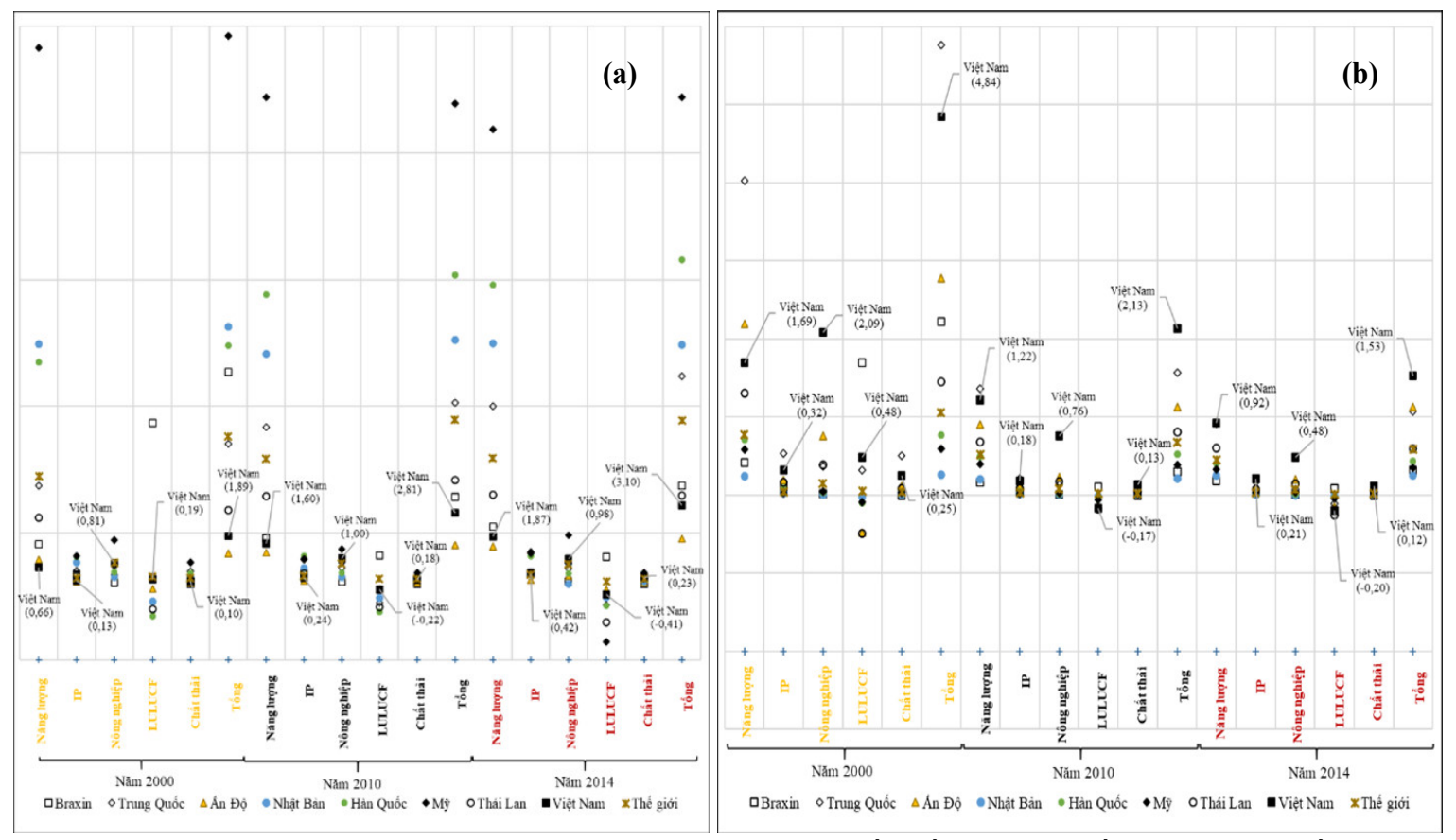

Hình 2. (a) Cường độ phát thải KNK của Việt Nam và một số quốc gia trên thế giới theo dân số giai đoạn 2000-2014; (b) Cường độ phát thải KNK của Việt Nam và một số quốc gia trên thế giới theo GDP giai đoạn 2000-2014 [11, 13-22].

\subsection{Phát thải KNK tại Việt Nam giai đoạn 2014-2030}

Xét theo lĩnh vực, lượng KNK phát thải trong cả năm lĩnh vực (năng lượng, nông nghiệp, IP, chất thải) đều có xu hướng tăng mạnh hơn trong giai đoạn 2014-2030 [5]. Cụ thể, theo dự báo, lượng KNK phát thải tăng từ 283,97 triệu tấn $\mathrm{CO}_{2}$ tđ (2014) lên 927,9 triệu tấn $\mathrm{CO}_{2}$ tđ (2030) (tăng 3,2 lần). Trong đó, phát thải trong lĩnh vực năng lượng chiếm tỷ lệ lớn nhất (chiếm $73,1 \%$ ), lĩnh vực IP vượt lên đứng vị trí thứ hai $(15,1 \%)$, lĩnh vực nông nghiệp đứng thứ ba (chiếm 12,1\%) và lĩnh vực chất thải đứng thứ tư (chiếm 5,0\%).

Bảng 2. Dự báo phát thải KNK của Việt Nam đến năm 2030 [5].

\begin{tabular}{lcccccccc}
\hline \multirow{2}{*}{ Lĩnh vụ̣c } & \multicolumn{2}{c}{ Năm 2014 } & \multicolumn{2}{c}{ Năm 2020 } & \multicolumn{2}{c}{ Năm 2025 } & \multicolumn{2}{c}{ Năm 2030 } \\
\cline { 2 - 9 } & $\begin{array}{c}\text { Lượng } \\
\text { phát thải }\end{array}$ & Tỷ lệ & $\begin{array}{c}\text { Lưọng } \\
\text { phát thải }\end{array}$ & Tỷ lệ & $\begin{array}{c}\text { Lượng } \\
\text { phát thải }\end{array}$ & Tỷ lệ & $\begin{array}{c}\text { Lượng } \\
\text { phát thải }\end{array}$ & Tỷ lệ \\
\hline Năng lượng & 171,62 & $53,4 \%$ & 347,5 & $61,6 \%$ & 500,7 & $65,5 \%$ & 678,4 & $69,4 \%$ \\
Nông nghiệp & 89,75 & $27,9 \%$ & 104,5 & $18,5 \%$ & 109,2 & $14,3 \%$ & 112,1 & $11,5 \%$ \\
IP & 38,62 & $12,0 \%$ & 80,5 & $14,3 \%$ & 116,1 & $15,2 \%$ & 140,3 & $14,4 \%$ \\
Chất thải & 21,51 & $6,7 \%$ & 31,3 & $5,6 \%$ & 38,1 & $5,0 \%$ & 46,3 & $4,7 \%$ \\
LULUCF & $-37,54$ & - & $-35,4$ & - & $-37,9$ & - & $-49,2$ & - \\
Tổng* & 321,5 & $100 \%$ & 563,8 & $100 \%$ & 764,1 & $100 \%$ & 977,1 & $100 \%$ \\
\hline
\end{tabular}

Ghi chú: Đơn vị lương phát thải KNK là triệu tấn CO tat; * Không bao gồm LULUCF.

Kết quả kiểm kê giai đoạn 2000-2014 và số liệu dự báo giai đoạn 2014-2030 cho thấy có sự thay đổi về thứ tự các lĩnh vực phát thải KNK (Hình 3). Theo đó, kể từ 2002, lĩnh vực năng lượng vượt qua nông nghiệp để trở thành lĩnh vực có tỷ lệ phát thải lớn nhất. Lĩnh vực các quá trình công nghiệp đứng vị trí thứ hai kể từ 2025 , thay thế cho nông nghiệp. Lĩnh vực chất thải chiếm tỷ lệ nhỏ nhất, đứng vị trí thứ tư. Từ năm 2005, LULUCF trở thành lĩnh vực hấp thụ KNK. 


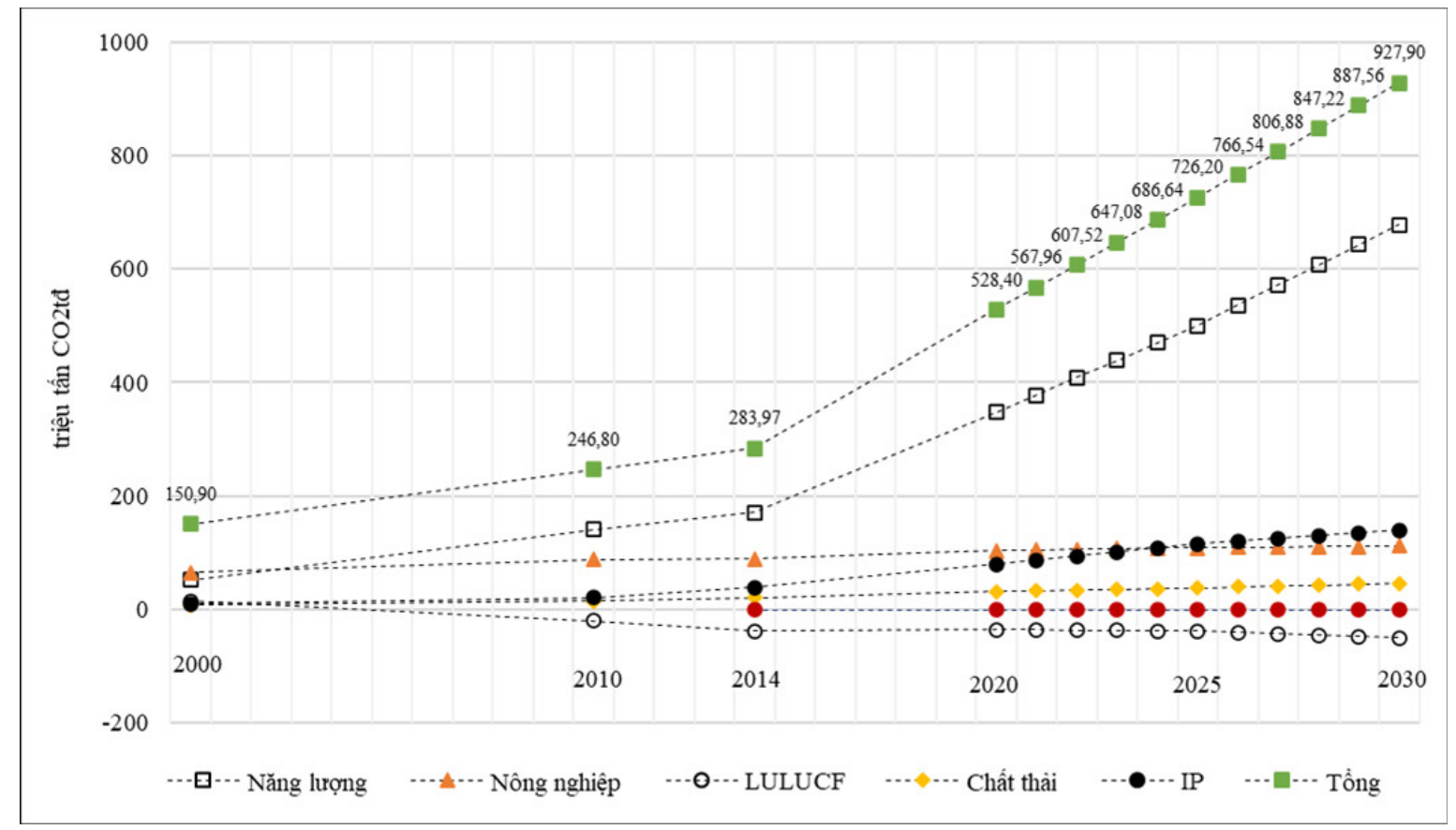

Hình 3. Dự báo phát thải KNK của Việt Nam đến năm 2030 [5].

\subsection{Một số co họi}

Kết quả phân tích cho thấy, lượng phát thải KNK của Việt Nam sẽ tăng nhanh. Theo cam kết, bằng nguồn lực trong nước, đến năm 2030 Việt Nam đặt mục tiêu sẽ giảm $9 \%$ tổng lượng phát thải KNK so với kịch bản BAU và có thể tăng lên tới $27 \%$ khi nhận được hỗ trợ quốc tế [5]. Theo đó, để thực hiện NDC, Việt Nam đã xác định 67 biện pháp liên ngành ưu tiên thực hiện gồm:

+ Năng lượng: 35 biện pháp. Trong đó, bằng nguồn lực quốc gia sẽ thực hiện 25 biện pháp. Khi có nguồn lực quốc tế sẽ thực hiện thêm 10 biện pháp, nâng mức độ giảm phát thải của 4 biện pháp do quốc gia tự thực hiện.

+ Nông nghiệp: 15 biện pháp. Trong đó, bằng nguồn lực quốc gia sẽ thực hiện 4 biện pháp. Khi có nguồn lực quốc tế sẽ thực hiện thêm 11 biện pháp.

+ LULUCF: 7 biện pháp. Trong đó, bằng nguồn lực quốc gia sẽ thực hiện 6 biện pháp. Khi có nguồn lực quốc tế sẽ thực hiện thêm 1 biện pháp, nâng mức độ hấp thụ/giảm phát thải của 5 biện pháp quốc gia thực hiện.

+ Chất thải: 5 biện pháp. Trong đó, bằng nguồn lực quốc gia sẽ thực hiện 4 biện pháp. Khi có nguồn lực quốc tế sẽ thực hiện thêm 1 biện pháp.

+ IP: 4 biện pháp. Trong đó, bằng nguồn lực quốc gia sẽ thực hiện 3 biện pháp. Khi có nguồn lực quốc tế sẽ thực hiện thêm 1 biện pháp.

Với 42 biện pháp ưu tiên thực hiện bằng nguồn lực trong nước, tiềm năng giảm giai đoạn 2021-2030 ước tính 529,7 triệu tấn $\mathrm{CO}_{2}$ tđ với chi phí ước tính khoảng 17,3 tỷ USD.

Đặc biệt, lượng KNK có thể giảm thêm 864,3 triệu tấn $\mathrm{CO}_{2}$ tđ nếu có nguồn lực quốc tế với chi phí ước tính khoảng 30,6 tỷ USD (Bảng 3). 


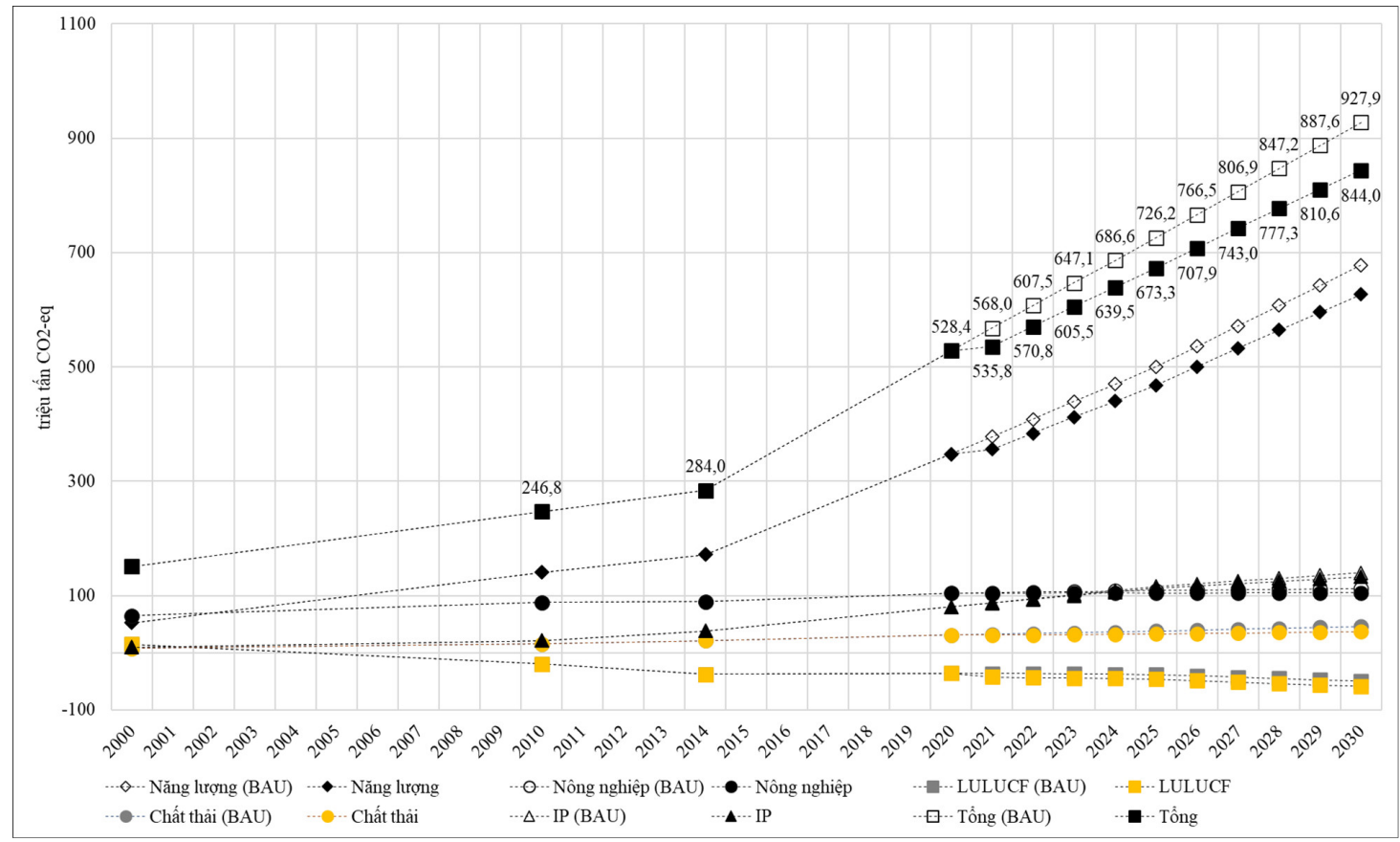

Hình 4. Dự báo phát thải KNK của Việt Nam đến năm 2030 theo kịch bản thông thường và kịch bản với mức đóng góp không điều kiện [5].

Bảng 3. Tiềm năng và chi phí giảm phát thải KNK tại Việt Nam đến năm 2030 [5].

\begin{tabular}{|c|c|c|c|c|c|c|c|c|c|}
\hline \multirow[b]{2}{*}{ Lĩnh vụcc } & \multicolumn{3}{|c|}{ Nguồn lực trong nước } & \multicolumn{3}{|c|}{ Nguồn lực quốc tế } & \multicolumn{3}{|c|}{ Tổng } \\
\hline & $\begin{array}{l}\text { Tiềm } \\
\text { năng }\end{array}$ & $\begin{array}{c}\text { Tổng } \\
\text { chi phí }\end{array}$ & $\begin{array}{c}\text { Chi phí } \\
\text { trung } \\
\text { bình }\end{array}$ & $\begin{array}{l}\text { Tiềm } \\
\text { năng }\end{array}$ & $\begin{array}{c}\text { Tổng } \\
\text { chi phí }\end{array}$ & $\begin{array}{l}\text { Chi } \\
\text { phí } \\
\text { trung } \\
\text { bình }\end{array}$ & $\begin{array}{l}\text { Tiềm } \\
\text { năng }\end{array}$ & $\begin{array}{c}\text { Tổng } \\
\text { chi phí }\end{array}$ & $\begin{array}{c}\text { Chi phí } \\
\text { trung } \\
\text { bình }\end{array}$ \\
\hline Năng lượng & 296,9 & $12.429,8$ & 41,9 & 424,6 & $22.377,0$ & 52,7 & 721,5 & $34.806,8$ & 48,2 \\
\hline Nông nghiệp & 44,7 & $1.390,2$ & 31,1 & 172,4 & $4.203,5$ & 24,4 & 217,1 & $5.593,7$ & 25,8 \\
\hline LULUCF & 81,2 & $1.950,7$ & 24,0 & 96,4 & $1.920,2$ & 19,9 & 177,6 & $3.870,9$ & 21,8 \\
\hline Chất thải & 62,8 & 780,0 & 12,4 & 166,0 & $1.903,7$ & 11,5 & 228,8 & $2.683,7$ & 11,7 \\
\hline IPPU & 44,1 & 713,9 & 16,2 & 4,9 & 197,9 & 40,4 & 49,0 & 911,8 & 18,6 \\
\hline Tổng & 529,7 & $17.264,6$ & 32,6 & 864,3 & $30.602,3$ & 148,9 & $1.394,0$ & $47.866,9$ & 34,3 \\
\hline
\end{tabular}

Ghi chú: Tiềm năng giảm phát thải (triệu tấn $\mathrm{CO}_{2}$ tđ), tổng chi phí (triệu USD), chi phí trung bình (USD/tấn $\mathrm{CO}_{2}$ tđ) được tính trong giai đoạn 2021-2030.

Về tổng quan, có thể thấy lĩnh vực năng lượng có nhiều cơ hội giảm phát thải nhất (chiếm 56,1\% tổng tiềm năng giảm phát thải với nguồn lực trong nước). Đặc biệt, với sự hỗ trợ của quốc tế, tiềm năng giảm phát thải trong lĩnh vực năng lượng có thể tăng lên khoảng 1,4 lần nữa, lên tới 424,6 triệu tấn $\mathrm{CO}_{2}$ tđ̛ và chiếm khoảng $52 \%$ tổng tiềm năng giảm trong giai đoạn 2021-2030. Tuy nhiên chi phí giảm phát thải còn khá cao. Điều này một phần là bởi các biện pháp giảm phát thải KNK trong lĩnh vực năng lượng đòi hỏi phải thay đổi kỹ thuật, thiết bị (thay thế đèn thắp sáng tiết kiệm điện, áp dụng công nghệ cải tiến trong sản xuất xỉ măng,...).

Trong khi đó, lĩnh vực nông nghiệp có tiềm năng giảm phát thải KNK tăng mạnh nhất (tăng 386\%) nếu có sự hỗ trợ của quốc tế. Điều này là bởi hiện nay các hoạt động sản xuất nông nghiệp của Việt Nam vẫn chủ yếu theo phương pháp truyền thống, phụ thuộc nhiều vào 
các yếu tố thâm dụng đầu vào (phân bón, nước,...). Các thực hành liên quan đến nông nghiệp bền vững giảm phát thải KNK (quản lý nước và tưới tiêu, tích hợp công nghệ khí sinh học trong chăn nuôi, cải thiện quản lý thức ăn gia súc,...) hiện được áp dụng tương đối hạn chế.

Đặc biệt, khi xem xét chi tiết các biện pháp trong cả 5 lĩnh vực, ta thấy có nhiều biện pháp có chi phí giảm phát thải ròng âm (Bảng 4). Ví dụ như biện pháp "chôn lấp chất thải rắn có thu hồi khí bãi rác cho phát điện" có chi phí giảm phát thải là $-0,5 \mathrm{USD} /$ tấn $\mathrm{CO}_{2}$ tđ. Trên thực tế, đây là những biện pháp mà ngoài lợi ích giảm phát thải KNK, khi thực hiện còn tạo ra được các lợi ích khác (ví dụ, cung cấp khí đốt phát điện), giúp tổng lợi ích lớn hơn tổng chi phí thực hiện. Khi đó, chi phí giảm phải thải ròng của biện pháp là âm. Đây là nhóm các biện pháp "không hối tiếc" (no-regret) mà các nhà phân tích thường rất khuyến khích thực hiện [23].

Bảng 4. Nhóm 24 biện pháp giảm phát thải có chi phí ròng âm và nhu cầu tài chính tương ứng trong giai đoạn 2021-2030 [5].

\begin{tabular}{|c|c|c|c|c|}
\hline \multirow[t]{2}{*}{ Biện pháp } & \multicolumn{2}{|c|}{$\begin{array}{c}\text { Tiềm năng giảm } \\
\text { phát thải }\end{array}$} & \multirow{2}{*}{$\begin{array}{c}\text { Chi phí } \\
\text { giảm phát } \\
\text { thải }\end{array}$} & \multirow[t]{2}{*}{$\begin{array}{l}\text { Nhu cầu tài chính } \\
\text { (2021-2030) }\end{array}$} \\
\hline & 2021-2030 & 2030 & & \\
\hline \multicolumn{5}{|l|}{ I. Lĩnh vực năng lượng } \\
\hline - Tối ưu hóa chu trình đốt clanker & 1,86 & 0,4 & $-6,4$ & 14,3 \\
\hline - Giảm tổn thất nhiệt lò nung clinker & 2,58 & 0,6 & $-11,5$ & 2,1 \\
\hline - Thu hồi nhiệt thải từ sản xuất xi măng & 9 & 1,8 & $-6,8$ & 221,8 \\
\hline $\begin{array}{l}\text { - Áp dụng công nghệ cải tiến trong sản xuất gạch } \\
\text { nung }\end{array}$ & 6,48 & 1,4 & $-11,8$ & 23,0 \\
\hline - Phun than antracit bột vào lò cao & 1,62 & 0,7 & $-10,8$ & 7,4 \\
\hline $\begin{array}{l}\text { - Nung nóng sơ bộ thép phế liệu trước khi đưa } \\
\text { vào lò điện hồ quang (EAF) }\end{array}$ & 2,46 & 0,6 & $-19,9$ & 11,6 \\
\hline - Gia nhiệt trong máy cán thép & 2,94 & 0,7 & $-15,1$ & 28,9 \\
\hline $\begin{array}{l}\text { - Giới hạn mức tiêu thụ nhiên liệu đối với xe cơ } \\
\text { giới sản xuất lắp ráp, nhập khẩu mới }\end{array}$ & 9,48 & 5,1 & $-65,5$ & 0,25 \\
\hline $\begin{array}{l}\text { - Chuyển đổi từ phương thức vận tải hành khách } \\
\text { từ sử dụng phương tiện cá nhân sang sử dụng } \\
\text { phương tiện giao thông công cộng }\end{array}$ & 2,76 & 0,4 & $-9,7$ & 257,2 \\
\hline $\begin{array}{l}\text { - Chuyển đổi từ vận tải đường bộ sang đường } \\
\text { thủy nội địa và ven biển }\end{array}$ & 9,6 & 1,6 & $-78,3$ & 176,7 \\
\hline - Sử dụng xe máy điện & $\begin{array}{c}2,76 \\
(4,68)\end{array}$ & $\begin{array}{l}0,6 \\
(1)\end{array}$ & $-67,2$ & $\begin{array}{c}157 \\
(267,0)\end{array}$ \\
\hline $\begin{array}{l}\text { - Sử dụng các thiết bị điện hiệu suất cao trong } \\
\text { dịch vụ thương mại }\end{array}$ & 13,98 & 3,8 & $-16,9$ & 84,0 \\
\hline $\begin{array}{l}\text { - Nâng cao hiệu quả sử dụng năng lượng trong } \\
\text { các phân ngành công nghiệp }\end{array}$ & $(52,44)$ & $(15)$ & $(-6,5)$ & $(918,3)$ \\
\hline - Tăng hệ số tải của ô tô tải & $(4,74)$ & $(1,3)$ & $(-40,8)$ & $(214,6)$ \\
\hline $\begin{array}{l}\text { - Chuyển đổi phương thức vận tải từ đường bộ } \\
\text { sang đường sắt }\end{array}$ & $(4,14)$ & $(1,1)$ & $(-67,8)$ & $(105,3)$ \\
\hline II. Lĩnh vực nông nghiệp & & & & \\
\hline - Chuyển đất chuyên lúa-lúa thành lúa-thủy sản & 7,2 & 1,3 & $-293,2$ & 181,8 \\
\hline
\end{tabular}




\begin{tabular}{|c|c|c|c|c|}
\hline \multirow[t]{2}{*}{ Biện pháp } & \multicolumn{2}{|c|}{$\begin{array}{c}\text { Tiềm năng giảm } \\
\text { phát thải }\end{array}$} & \multirow{2}{*}{$\begin{array}{c}\text { Chi phí } \\
\text { giảm phát } \\
\text { thải }\end{array}$} & \multirow[t]{2}{*}{$\begin{array}{l}\text { Nhu cầu tài chính } \\
\text { (2021-2030) }\end{array}$} \\
\hline & 2021-2030 & 2030 & & \\
\hline - Chuyển đất lúa thành đất cây trồng cạn. & 7,9 & 1,4 & $-0,1$ & 0,036 \\
\hline \multicolumn{5}{|l|}{ III. Lĩnh vực LULUCF } \\
\hline - Bảo tồn và bảo vệ diện tích rừng tự nhiên hiện & 51,7 & 6 & $-4,8$ & $1.562,2$ \\
\hline có ở vùng đồi núi & $(32,9)$ & $(4,4)$ & $(-5,2)$ & $(1.247,8)$ \\
\hline - Bảo tồn và bảo vệ rừng ven biển & 4,4 & 0,5 & $-4,8$ & 133,9 \\
\hline - Nâng cao năng suất và trữ lượng các-bon của & 6,4 & 0,8 & $-5,7$ & 62 \\
\hline rừng trồng gỗ lớn & $(14,1)$ & $(1,8)$ & & (244) \\
\hline - Quản lý rừng bền vững và chứng chỉ rừng & 14,7 & 1,7 & $-1,1$ & 38,4 \\
\hline & $(18,9)$ & $(2,3)$ & $(-3,4)$ & $(330,9)$ \\
\hline \multicolumn{5}{|l|}{ IV. Lĩnh vực chất thải } \\
\hline - Chôn lấp chất thải rắn có thu hồi khí bãi rác cho & 1,7 & 0,3 & $-0,5$ & 10,1 \\
\hline phát điện & $(4,4)$ & $(0,7)$ & & $(1,8)$ \\
\hline - Chôn lấp bán hiếu khí & 6 & 1 & $-73,4$ & 12,9 \\
\hline & $(15,9)$ & $(2,7)$ & & $(24,5)$ \\
\hline - Sản xuất phân hữu cơ từ chất thải rắn & 44,7 & 7,6 & -20 & 197,6 \\
\hline & $(117,9)$ & $(19,9)$ & & $(31,6)$ \\
\hline - Sản xuất tấm nhiên liệu RDF & $(0,3)$ & $(0,1)$ & $(-232,7)$ & $(1.364,2)$ \\
\hline \multicolumn{5}{|l|}{ V. Lĩnh vực IPPU } \\
\hline $\begin{array}{l}\text { - Nghiền tro bay thay thế clinker trong thành } \\
\text { phần xi măng }\end{array}$ & 10,3 & 2 & -50 & 543,4 \\
\hline $\begin{array}{l}\text { - Nghiền Pozzolana thay thế clinker trong thành } \\
\text { phần xi măng }\end{array}$ & 10,3 & 2 & -61 & 152,4 \\
\hline $\begin{array}{l}\text { - Nghiền đá vôi thay thế clinker trong thành } \\
\text { phần xi măng }\end{array}$ & 16,4 & 3,2 & -64 & 18,1 \\
\hline $\begin{array}{l}\text { - Nghiền xì lò thổi (GBFS) thay thế clinker trong } \\
\text { thành phần xi măng }\end{array}$ & $(4,1)$ & $(0,8)$ & $(-50)$ & $(197,9)$ \\
\hline \multirow[t]{2}{*}{ Tổng } & 247,22 & 45,5 & & $3.896,9$ \\
\hline & $(274,5)$ & $(51,1)$ & & $(4.947,8)$ \\
\hline
\end{tabular}

Ghi chú: Trong dấu ngoặc thể hiện sự hỗ trợ của tổ chức quốc tế; Tiềm năng giảm phát thải đơn vị là triệu tấn CO 2 tđ; Tổng chi phí đơn vị là triệu USD; Chi phi trung bình đơn vị là USD/tấn CO 2 tđa.

Như vậy, 24 biện pháp có chi phí ròng âm nên được ưu tiên, nhu cầu tài chính dành cho các nhóm biện pháp này ước tính khoảng 3,9 tỉ USD trong giai đoạn 2021-2030. Theo đó, tổng lượng KNK ước tính giảm được của riêng năm 2030 nhờ các biện pháp này là 45,5 triệu tấn $\mathrm{CO}_{2}$ tđ, tương đương với mức giảm $4,9 \%$ so với Kịch bản $\mathrm{BAU}$ quốc gia, tức đạt hơn một nửa $(54,2 \%)$ so với mức cam kết $9 \%\left(83,9\right.$ triệu tấn $\mathrm{CO}_{2}$ tđ) theo NDC cập nhật. Hơn nữa, với sự hỗ trợ từ quốc tế, có thể thực hiện tới 29 biện pháp, nhu cầu tài chính ước tính 8,84 tỉ USD (hỗ trợ quốc tế chiếm khoảng 56\%). Tổng lượng giảm phát thải ước tính nhờ các biện pháp "không hối tiếc" này tương đương khoảng 10,4\% tổng lượng phát thải theo dự báo cho năm 2030, đạt 38,5\% so với mức cam kết $27 \%$ theo NDC cập nhật.

Nói tóm lại, các biện pháp "không hối tiếc", tức đảm bảo chắc chắn đem lại lợi nhuận khi thực hiện, sẽ đóng góp từ 38,5\% đến 54,2\% cam kết giảm phát thải KNK theo NDC cập nhật của Việt Nam. Các phân tích được trình bày ở đây còn chưa tính toán tới các tác động ngoại 
ứng tích cực của các biện pháp này, giúp thúc đẩy nỗ lực giảm phát thải KNK trong các lĩnh vực khác của toàn nền kinh tế. Tuy nhiên, điều này càng cho thấy Việt Nam đang có nhiều cơ hội thực hiện thành công các cam kết trong NDC cập nhật.

Ngoài ra, hiện nay Việt Nam đã có một hệ thống chính sách liên quan đến giảm nhẹ phát thải KNK (Hình 5). Hiện tại, các chính sách và các văn bản dưới Luật được Chính phủ và các Bộ, ngành đã ban hành là trên 300 văn bản quan trọng, trong đó có 67 văn bản do Chính phủ ban hành trực tiếp hoặc gián tiếp liên quan tới BĐKH [5]. Điều này đang tạo ra những cơ hội thúc đẩy giảm phát thải KNK trong đa dạng lĩnh vực.

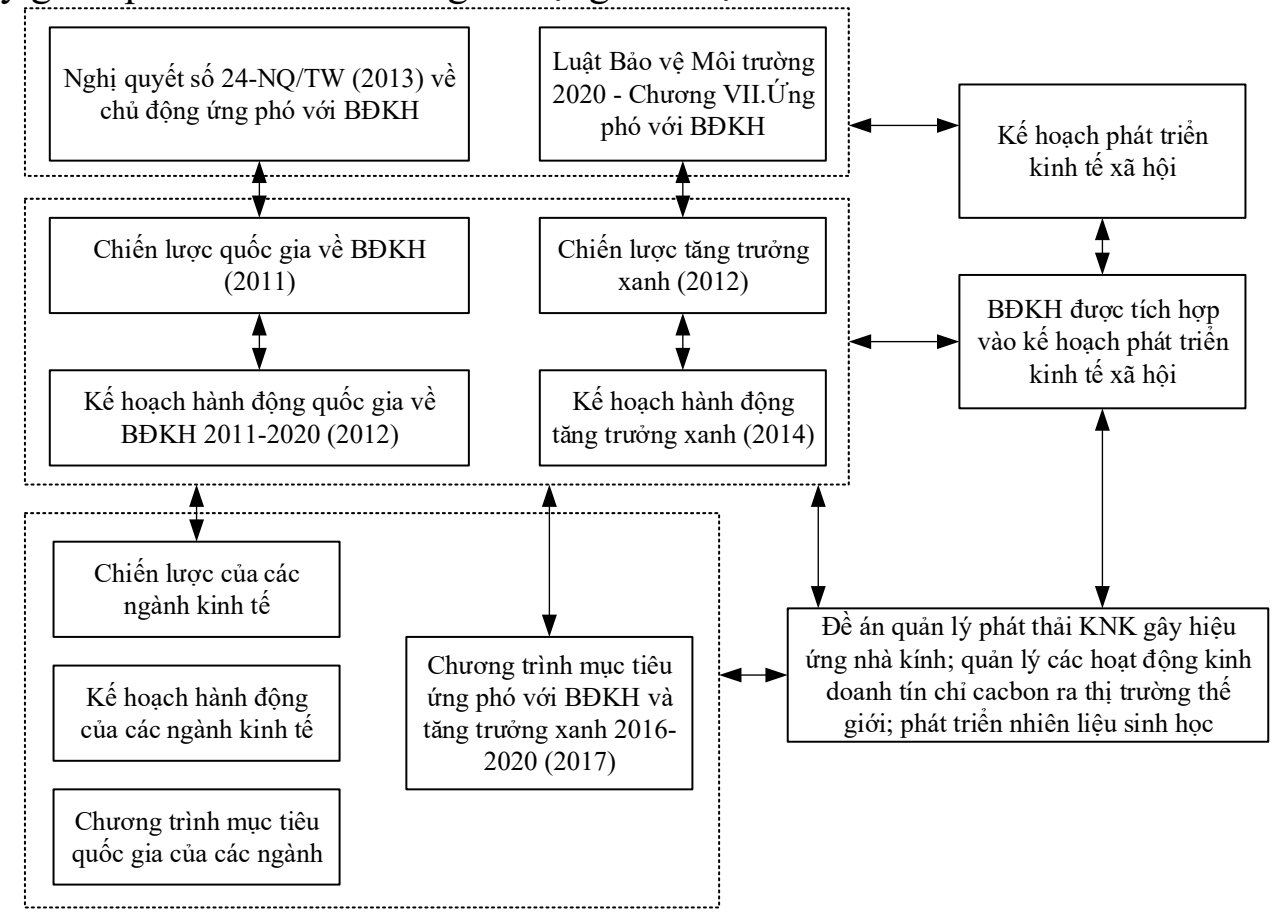

Hình 5. Hệ thống chính sách liên quan đến giảm nhẹ phát thải KNK tại Việt Nam [24].

Tại Việt Nam, triển khai các cơ chế quốc tế liên quan các hoạt động giảm nhẹ phát thải khí nhà kính, 257 dự án theo Cơ chế Phát triển sạch $(\mathrm{CDM})$ và 13 Chương trình hoạt động theo CDM (PoA) đã được triển khai [25]. Bên cạnh đó, một số cơ chế tạo tín chỉ các-bon theo hình thức tự nguyện (Tiêu chuẩn vàng-GS, Tiêu chuẩn các-bon được thẩm tra-VCS) cũng đã được thực hiện. Từ năm 2021 trở đi, các cơ chế theo quy định tại Điều 6 Thỏa thuận Paris về BĐKH cũng sẽ được áp dụng, bao gồm: cơ chế đóng góp giảm nhẹ phát thải KNK và hỗ trợ phát triển bền vững (SDM), cơ chế buôn bán kết quả giảm nhẹ phát thải quốc tế (ITMO) [25]. Việc thực hiện các hoạt động giảm phát thải theo các cơ chế này này sẽ giúp tạo ra một kênh đầu tư mới; các doanh nghiệp được tiếp cận và áp dụng các công nghệ, sản phẩm, hệ thống, dịch vụ các-bon thấp tiên tiến và được tăng cường năng lực trong thực hiện các hoạt động giảm nhẹ phát thải KNK theo tiêu chuẩn quốc tế; góp phần thúc đẩy sự phát triển của một xã hội các-bon thấp [26].

Đồng thời, hiện nay Nghị định hướng dẫn thi hành Luật Bảo vệ môi trường 2020 đang được soạn thảo, trong đó có nội dung về thị trường các-bon, thuế các-bon và chi trả dịch vụ hấp thụ và lưu trữ các-bon của các hệ sinh thái,...Đây sẽ là những chính sách sẽ có tác động thúc đẩy mạnh mẽ nỗ lực giảm phát thải KNK trong mọi hoạt động của xã hội.

\subsection{Một số thách thức}

Để giảm phát thải KNK từ kịch bản BAU sang kịch bản phát thải cacbon thấp, Việt Nam đang phải đối mặt với nhiều thách thức. Chỉ riêng thực hiện 42 biện pháp ưu tiên với nguồn lực trong nước, kinh phí ước tính cần khoảng 1,7 tỷ USD mỗi năm trong giai đoạn 
2021-2030 (chiếm khoảng 0,7\% GDP hàng năm). Theo số liệu của Bộ Tài chính, tổng chi cho các nhiệm vụ bảo vệ môi trường nói chung trong giai đoạn 2013-2018 là 72.422 tỷ đồng (tương đương 0,5 tỷ USD/năm). Trong hoạt động ứng phó với BĐKH, nguồn kinh phí phân bổ vẫn tập trung vào các dự án cơ sở hạ tầng quy mô lớn để tăng cường năng lực chống chịu. Ngân sách đầu tư cho hoạt động giảm phát thải KNK chỉ chiếm tỷ lệ rất nhỏ [27].

Nghiên cứu này đã thực hiện tổng hợp những thách thức đối với giảm phát thải KNK tại Việt Nam, được phát hiện và trình bày bởi một số nghiên cứu khoa học tiêu biểu (gồm các bài báo được công bố trên các tạp chí uy tín, các báo cáo kỹ thuật liên quan đến đóng góp do quốc gia tự quyết định của Việt Nam và các luận án tiến sĩ liên quan) trong khoảng 10 năm gần đây, từ 2011 đến 2021 (Bảng 5).

Bảng 5. Các thách thức đối với giảm phát thải KNK tại Việt Nam.

\begin{tabular}{lcc}
\hline & Thách thức & Nguồn \\
\hline Chính sách
\end{tabular}

Chính sách

- Thiếu hướng dẫn và cơ chế để chuyển kế hoạch NDC quốc gia hoặc ngành sang kế hoạch ở cấp địa phương. Thiếu hướng dẫn lập kế hoạch cấp tỉnh và cấp ngành để thực hiện hoặc lồng ghép NDC.

- Chưa có quy định cụ thể về chế độ báo cáo tình hình thực hiện dự án đối với các bên tham gia dự án theo cơ chế phát triển sạch, chưa có chế tài xử lý vi phạm đối với hoạt động thực hiện dự án.

- Chưa có môi trường pháp lý đủ hấp dẫn với các nhà tài trợ quốc tế, khối doanh nghiệp và tư nhân đầu tư giảm nhẹ BĐKH.

- Quy định về tiêu chuẩn công nghệ, dán nhãn thiết bị đã có hiệu lực, song việc thực hiện còn chậm; chưa có quy định chặt chẽ về danh mục dán nhãn cũng như tiêu chuẩn cho các loại thiết bị, máy móc.

- Sự tham gia của các bên liên quan (đặc biệt là khu vực tư nhân) trong quá trình xây dựng, phản hồi chính sách còn hạn chế.

- Chưa có cơ chế chính sách cụ thể, cơ chế tài chính đủ hấp dẫn để thu hút sự tham gia của khu vực tư nhân trong các hoạt động giảm phát thải KNK.

- Chưa có cơ chế chính sách cụ thể để thu hút sự tham gia của các doanh nghiệp vừa và nhỏ trong các hoạt động giảm phát thải KNK.

- Thể chế, chính sách về quản lý và hỗ trợ xử lý chất thải nói chung và khí thải nói riêng chưa hoàn thiện, còn chồng chéo và thực thi chưa tốt.

\section{Tài chính, kỹ thuật và nhân lực}

- Vốn đầu tư ban đầu cho các giải pháp giảm phát thải KNK thường cao, trong khi tài chính cho các hoạt động giảm phát thải KNK còn hạn chế.

- Cơ hội tiếp cận nguồn vốn tín dụng ưu đãi để thực hiện các biện pháp giảm phát thải KNK còn hạn chế.

- Năng lực nói chung của doanh nghiệp (năng lực tài chính, năng lực tiếp nhận, vận dụng các công nghệ mới) còn hạn chế.

- Thị trường công nghệ tiết kiệm năng lượng và năng lượng tái tạo ở Việt Nam còn hạn chế.

- Số lượng, năng lực và trình độ của đội ngũ cán bộ quản lý, cán bộ khoa học kỹ thuật còn hạn chế. 
Thông tin và dữ liệu

- Chưa có hệ thống đo đạc, báo cáo và thẩm định (MRV) hoạt động giảm phát thải KNK ở cấp quốc gia và cấp ngành.

- Các báo cáo kiểm kê KNK có tính không chắc chắn khá cao do thông tin, số liệu còn thiếu và chưa đồng bộ, độ tin cậy chưa cao, việc quản lý còn chưa thống nhất.

- Thiếu công khai, minh bạch trong dự án các thu hút tư nhân tham gia.

- Hoạt động điều tra và thông tin kết quả điều tra đối với các nguồn năng lượng tái tạo còn hạn chế.

- Thiếu các nghiên cứu khoa học và công nghệ phục vụ giảm phát thải KNK.

- Doanh nghiệp thiếu các thông tin về chính sách, chưa nắm rõ các cơ chế và thủ tục pháp lý nên các dự án thường rất chậm được thông qua.

- Nhận thức của chính quyền, doanh nghiệp và người dân về các giải pháp giảm phát thải KNK còn hạn chế.

Bảng 5 cho thấy trong tổng số 20 thách thức đã liệt kê, có 5 thách thức được nhiều nghiên cứu tập trung phân tích, gồm: (i) Thiếu hướng dẫn, cơ chế và kế hoạch để thực hiện giảm phát thải KNK theo NDC ở cấp địa phương; (ii) Vốn đầu tư ban đầu cho các giải pháp giảm phát thải KNK thường cao, trong khi đó tài chính cho các hoạt động giảm phát thải KNK còn hạn chế; đặc biệt (iii) Chưa có cơ chế chính sách đủ hấp dẫn để thu hút sự tham gia của khu vực tư nhân trong các hoạt động giảm phát thải KNK; (iv) Năng lực của doanh nghiệp (cả về tài chính và kỹ thuật công nghệ) còn hạn chế; và (v) Nhận thức chung của xã hội về các giải pháp giảm phát thải KNK còn hạn chế.

Việc có nhiều nghiên cứu cùng phát hiện ra 5 vấn đề này cho thấy đây chính là những thách thức nổi bật nhất đối với nỗ lực giảm phát thải KNK của Việt Nam. Trong đó, những thách thức về chính sách sẽ đòi hỏi thời gian hoàn thiện và ban hành các hướng dẫn chi tiết cho việc thực hiện. Các vấn đề về tài chính, kỹ thuật và nhân lực cũng cần nhiều thời gian để cải thiện, hơn nữa việc huy động các nguồn lực này thường cần chính sách đi trước tạo điều kiện phù hợp. Thách thức về nhận thức chung của xã hội cũng đòi hỏi thời gian thiết kế và thực hiện các chương trình đào tạo, nâng cao nhận thức cho nhiều đối tượng khác nhau trong xã hội. Như vậy, có thể thấy các thách thức trên đều chỉ có thể được giải quyết triệt để trong dài hạn. Do đó, những nỗ lực cải thiện cần được bắt đầu sớm nhất có thể.

Trước mắt, về chính sách, nên tập trung vào việc ban hành kế hoạch thực hiện NDC ở các cấp độ và tạo cơ chế thu hút khu vực tư nhân tham gia trong việc giảm phát thải KNK. Hiện tại, trong các chính sách ứng phó với $\mathrm{BĐKH} \mathrm{quốc} \mathrm{gia,} \mathrm{nội} \mathrm{dung} \mathrm{liên} \mathrm{quan} \mathrm{đến} \mathrm{vai} \mathrm{trò} \mathrm{của}$ doanh nghiệp còn rất hạn chế. Hầu hết các văn bản chính sách trước 2015 đều không đề cập hoặc đề cập rất ít đến vai trò của doanh nghiệp [34]. Cần lưu ý rằng ngay cả các biện pháp được coi là "không hối tiếc" và đáng được ưu tiên thực hiện nhưng cũng cần có tài chính cho các khoản đầu tư trước (thay đổi thiết bị, thay đổi mô hình hay chuỗi sản xuất). Vì vậy, việc thu hút đa dạng các nguồn lực, đặc biệt là nguồn lực từ khu vực tư nhân sẽ giúp giải quyết được tốt hơn thách thức về tài chính này. Tiếp theo đó, chính các biện pháp "không hối tiếc" này sẽ tạo ra lợi ích ròng cho các bên thực hiện, đồng thời tạo hiệu ứng kéo theo việc giảm phát thải KNK trong các lĩnh vực khác. Trong quá trình tham gia thực hiện này, nhận thức của các bên liên quan cũng sẽ được nâng cao, kêt hợp với các chương trình đào tạo và nâng cao nhận thức, giúp việc giảm phát thải KNK được lồng ghép mở rộng trong mọi hoạt động kinh tế-xã hội.

Bên cạnh đó, cũng cần nghiên cứu, thiết kế và áp dụng các cơ chế thúc đẩy giảm phát thải như thị trường mua bán phát thải; chi trả dịch vụ hấp thụ và lưu giữ các-bon của hệ sinh thái;...) để tạo nguồn tài chính bền vững hỗ trợ thực thi các biện pháp giảm phát thải. 


\section{Kết luận}

Mặc dù phát thải KNK của Việt Nam hiện chưa lớn nhưng đang gia tăng với tốc độ cao (tăng 1,88 lần trong giai đoạn 2000-2014 và dự báo sẽ tăng hơn 3 lần trong giai đoạn 2014-2030 nếu không có các biện pháp tích cực). Nghiên cứu này thực hiện phân tích trong các giai đoạn 2000-2014 và 2014-2030 cho thấy có sự thay đổi về thứ tự các lĩnh vực phát thải. Kể từ năm 2002, năng lượng đã vượt qua nông nghiệp, trở thành lĩnh vực phát thải lớn nhất (chiếm 53,4\% năm 2014 và $71,3 \%$ năm 2030). Đến năm 2025, phát thải trong lĩnh vực IP theo dự báo vượt lên đứng thứ hai (chiếm 15,2\% năm 2025 và 14,4\% năm 2030). Tỷ lệ phát trong nông nghiệp giảm mạnh, từ đứng thứ nhất vào năm 2020 (chiếm 47,9\%) tụt xuống vị trí thứ ba kể từ năm 2025 và chiếm $11,5 \%$ tổng lượng phát thải $\mathrm{KNK}$ quốc gia vào năm 2030. Phát thải trong lĩnh vực chất thải chiếm tỷ lệ nhỏ nhất (chiếm 5,8\% năm 2020, giảm xuống còn $4,7 \%$ vào năm 2030). Lĩnh vực LULUCF chuyển từ phát thải KNK năm 2000 sang hấp thụ kể từ năm 2005.

Bài báo này cũng phân tích các cơ hội giảm phát thải của Việt Nam. Đó trước hết là các biện pháp "không hối tiếc" (no-regret) có chi phí giảm phát thải ròng âm, với tổng tiềm năng giảm phát thải năm 2030 ước tính 45,5 triệu tấn $\mathrm{CO}_{2}$ tđ (chiếm $4,9 \%$ tổng lượng phát thải theo dự báo) và tổng nhu cầu tài chính để thực hiện trong giai đoạn 2021-2030 ước tính khoảng 3,9 tỷ USD. Khi ngân sách quốc gia còn hạn chế, việc giảm phát thải KNK trước hết cần ưu tiên những biện pháp này. Ngoài ra, nghiên cứu đã chỉ ra và phân tích 05 thách thức chính đối với việc giảm phát thải KNK. Đó là thách thức về chính sách gồm (i) Thiếu hướng dẫn, cơ chế và kế hoạch để thực hiện giảm phát thải KNK theo NDC ở cấp địa phương; (ii) Chưa có cơ chế chính sách đủ hấp dẫn để thu hút sự tham gia của khu vực tư nhân trong các hoạt động giảm phát thải KNK; và những thách thức về nguồn lực, đặc biệt là (iii) Vốn đầu tư ban đầu cho các giải pháp giảm phát thải $\mathrm{KNK}$ thường cao, trong khi đó tài chính cho các hoạt động giảm phát thải KNK còn hạn chế; (iv) Năng lực tài chính và kỹ thuật của doanh nghiệp chưa cao và (v) Nhận thức chung của xã hội về các giải pháp giảm phát thải KNK còn hạn chế. Theo đó, các vấn đề cần tập trung trước hết là ban hành kế hoạch thực hiện NDC ở các cấp và tạo cơ chế thu hút khu vực tư nhân tham gia trong việc giảm phát thải KNK; ưu tiên thực hiện 24 biện pháp giảm phát thải "không hối tiếc", từ đó tạo hiệu ứng dẫn dắt nỗ lực chung trong các lĩnh vực khác; kết hợp với các chương trình đào tạo và nâng cao nhận thức nhằm mở rộng việc áp dụng các biện pháp giảm phát thải KNK trong mọi hoạt động kinh tế-xã hội.

Đóng góp cho nghiên cứu: Xây dựng ý tưởng nghiên cứu: N.H.N.; Lựa chọn phương pháp nghiên cứu: N.H.N., N.V.H.; Thu thập, phân tích, xử lý số liệu: N.V.H.; Viết bản thảo bài báo: N.V.H.; Chỉnh sửa bài báo: N.H.N.

Lời cảm ơn: Nghiên cứu này được thực hiện trong khuôn khổ của đề tài khoa học công nghệ cấp Bộ "Nghiên cứu, đề xuất chính sách huy động nguồn lực của khu vực tu nhân trong hoạt động giảm phát thải khí nhà kính tại Việt Nam”, mã số TNMT.2018.05.12.

Lời cam đoan: Tập thể tác giả cam đoan bài báo này là công trình nghiên cứu của tập thể tác giả, chưa được công bố ở đâu, không sao chép từ nghiên cứu trước đây; không có sự tranh chấp lợi ích trong nhóm tác giả.

\section{Tài liệu tham khảo}

1. Gao, Y.; Gao, X.; Zhang, X. The $2^{\circ} \mathrm{C}$ global temperature target and the evolution of the long-term goal of addressing climate change-from the United Nations framework convention on climate change to the Paris agreement. Eng. 2017, 3(2), 272-278. https://doi.org/10.1016/J.ENG.2017.01.022. 
2. Mulia, R.; Nguyen, D.D.; Nguyen, M.P. Enhancing Vietnam's Nationally Determined Contribution with Mitigation Targets for Agroforestry: A Technical and Economic Estimate. Land 2020, 9(12), 528. https://doi.org/10.3390/land9120528.

3. Bộ Tài nguyên và Môi trường. Báo cáo kỹ thuật Đóng góp dự kiến do Quốc gia tự quyết định của Việt Nam (INDC), Hà Nội, Việt Nam, 2015.

4. Quyết định số 2053/QĐ-TTg ngày 28 tháng 10 năm 2016 ban hành Kế hoạch hành động thực hiện Thỏa thuận Paris về Biến Đổi Khí hậu, 2016.

5. Bộ Tài nguyền và Môi trường. Báo cáo kỹ thuật đóng góp do quốc gia tự quyết định của Việt Nam (cập nhật năm 2020), Hà Nội, Việt Nam, 2020.

6. UNFCCC. Time Series - Annex I: GHG total with LULUCF, in $\mathrm{kt} \mathrm{CO}_{2}$ equivalent, 2021. Online avaliable: https://di.unfccc.int/time_series (truy cập: 25/03/2021).

7. Climate Watch. Climate Analysis Indicators Tool (CAIT). 2021. Online avaliable: https://www.climatewatchdata.org/data-explorer/ (truy cập: 10/04/2021).

8. Mitchell, N.; Triska, M.; Liberatore, A.; Ashcroft, L. Weatherill, R. \& Longnecker, $\mathrm{N}$. Benefits and challenges of incorporating citizen science into university education. PLoS One 2017, 12(11), 1-15. https://www.doi.org/10.1371/journal.pone.0186285

9. Friedrich, J.; Ge, M.; Pickens, A. This Interactive Chart Shows Changes in the World's Top 10 Emitters, World Resources Institute, 2020. https://www.wri.org/insights/interactive-chart-shows-changes-worlds-top-10-em itters

10. Environment and Climate Change Canada. Canadian Environmental Sustainability Indicators: Global greenhouse gas emissions. Consulted on month day, year, 2021. www.canada.ca/en/environment-climate-change/services/environmental-indicator s/globalgreenhouse-gas-emissions.html

11. Bộ Tài nguyên và Môi trường. Thông báo quốc gia lần thứ hai của Việt Nam cho Công ước khung của Liên Hợp Quốc về Biến đổi khí hậu, Hà Nội, Việt Nam, 2010.

12. Bộ Tài nguyên và Môi trường. Báo cáo cập nhật hai năm một lần lần thứ nhất của Việt Nam cho Công ước khung của Liên Hợp Quốc về Biến đổi khí hậu, Hà Nội, Việt Nam, 2014.

13. Bộ Tài nguyên và Môi trường. Thông báo quốc gia lần thứ ba của Việt Nam cho Công ước khung của Liên Hợp Quốc về Biến đổi khí hậu, Hà Nội, Việt Nam, 2019.

14. EPA. Inventory of U.S. Greenhouse Gas Emissions and Sinks: 1990-2011, 2013. https://www.epa.gov/sites/production/files/2015-12/documents/us-ghg-inventory2013-main-text.pdf.

15. EPA. Inventory of U.S. Greenhouse Gas Emissions and Sinks: 1990-2018, 2020. https://www.epa.gov/sites/production/files/2020-04/documents/us-ghg-inventory2020-main-text.pdf.

16. Government of India. Third Biennial Update Report of India to the UNFCCC, 2021. https://unfecc.int/documents/268470.

17. Government of Japan. Japan's Seventh National Communication under the UNFCCC, 2017. https://unfecc.int/documents/193414.

18. Government of Japan. Report on the Technical Review of the Fourth Biennial Report of Japan, 2021. https://unfccc.int/documents/268441.

19. Government of Thailand. Thailand's Third National Communication to the UNFCCC, 2018. https://unfecc.int/documents/181765.

20. Government of Thailand. Thailand's Third Biennial Update Report to the UNFCCC, 2020. https://unfccc.int/documents/267629.

21. Government of the Republic of Korea. Third Biennial Update Report of the Republic of Korea under the UNFCCC, 2019. https://unfccc.int/documents/202576.

22. Worldbank. Số liệu về dân số và GDP, 2020. https://data.worldbank.org/indicator (truy cập: 10/04/2021).

23. Nguyen, H.N. Some economics of climate change adaptation in Vietnam, Doctor of Philosophy Ph.D. Thesis, La Trobe University, Melbourne, Australia, 2014. http://arrow.latrobe.edu.au:8080/vital/access/manager/Repository/latrobe:37965. 
24. Cục Biến đổi khí hậu. Giảm nhẹ phát thải khí nhà kính quốc gia và vai trò của khối tư nhân, Hội thảo tham vấn và đối thoại về đánh giá công nghệ các bon thấp (28/08/2017), Hà Nội, Việt Nam, 2017.

25. Minh, N.V.; Phong, N.V.; Anh, N.Q.; My, P.T.T.; Huyền, N.D. Vai trò của thị trường các-bon trong việc hỗ trợ thực hiện NDC - co hội và thách thức khi triển khai tại Việt Nam. Tạp chí Khoa học Biến đổi khi hậu 2020, 16, 36-47.

26. Công, N.T.; Dũng, T.T. Đánh giá tình hình thực hiện Cơ chế tín chỉ chung JCM tại Việt Nam: Kinh nghiệm để tiến tới triển khai Điều 6 của Thỏa thuận Paris về biến đổi khí hậu. Tạp chi Khí tượng Thủy văn 2020, 715, 49-58. https://doi.org/10.36335/VNJHM.2020(715).68-77.

27. Đạt, T.T.; Trường, Đ.Đ. Tài chính ứng phó với biến đổi khí hậu ở Việt Nam và hàm ý về chính sách. Tạp chí Tài chính 2019. Online available: https://tapchitaichinh.vn/nghien-cuu-trao-doi/tai-chinh-ung-pho-voi-bien-doi-khi-h au-o-viet-nam-va-ham-y-ve-chinh-sach-305149.html.

28. Pham, T.T.; Hoang, T.L.; Nguyen, D.T.; Dao, T.L.C.; Ngo, H.C.; Pham, V.H. The context of REDD+ in Vietnam: Drivers, agents and institutions, Occasional Paper 196, CIFOR, Indonesia, 2019. https://doi.org/10.17528/cifor/007402.

29. Trung, N.D.; Thang, N.T.; Babu, T.A.; Sebastian, L. Analysing the challenges in implementing Vietnam's Nationally-Determined Contribution (NDC) in the agriculture sector under the current legal, regulatory and policy environment. Cogent Environ. Sci. 2020, 6(1), 1792670. https://doi.org/10.1080/23311843.2020.1792670

30. Quang, N.T.; Hương, H.T.L.; Hiển, N.X.; Trà, T.V; Nhung, D.H. Đánh giá những thành quả nghiên cứu về biến đổi khí hậu, quản lý tài nguyên và môi trường tại Việt Nam và định hướng nghiên cứu trong giai đoạn tiếp theo. Tạp chi Khi turợng Thưy văn 2020, 714, 40-49. https://doi.org/10.36335/VNJHM.2020(714).40-49.

31. Tuệ, N.V.; Nhật, L.M.; Liên, M.K. Kết quả thực hiện chính sách, pháp luật vể biến đổi khí hậu ở Đồng bằng sông Cửu Long. Tạp chí Khi tuợng Thủy văn 2014, 646, $10-14$.

32. Thuận, H.T. Nghiên cứu cơ sở khoa học về hợp tác công tư trong ứng phó với biến đổi khí hậu ở Việt Nam. Luận án Tiến sỹ, Viện Khoa học Khí tượng Thủy văn và Biến đổi khí hậu, Hà Nội, Việt Nam, 2020.

33. Thái, T.H. Hoan, H.V.; Hương, P.T.T.; Liên, M.K.; Anh, T.Đ. Kinh nghiệm của một số nước trên thế giới trong huy động, quản lý, sử dụng các nguồn tài chính ứng phó với biến đổi khí hậu và giải pháp của Việt Nam. Tạp chi Khí tượng thủy văn 2014, $643,45-51$.

34. Huy, N; Thi, T.T.M.; Quang, V.Đ.Đ.; Nga, T.T.T. Sự tham gia của thành phần tư nhân thực hiện Kế hoạch quốc gia thích ứng với biến đổi khí hậu tại Việt Nam, Cục Biến đồi khí hậu, Hà Nội, Việt Nam, 2020.

35. Giles, J.; Grosjean, G.; Le Coq, J.F.; Huber, B.; Le, B.V.; Läderach, P. Barriers to implementing climate policies in agriculture: A case study from Viet Nam. Front. Sustainable Food Syst. 2021, 5, 1-15. https://doi.org/10.3389/fsufs.2021.439881.

36. Audinet, P.; Singh, B.; Kexel, D.T.; Suphachalasai, S.; Makumbe, P.; Mayer, K. Exploring a Low-Carbon Development Path for Vietnam. Directions in Development-Environment and Sustainable Development, World Bank, Washington, DC, 2016. https://openknowledge.worldbank.org/handle/10986/23522

37. Hai, N.H.; Anh, T.T. The Vietnamese Enterprise's Technological Capacity in the Context of the 4th Industrial Revolution. VNU J. Sci.: Policy Manage. Studies 2019, 35(3), 1-11. https://doi.org/10.25073/2588-1116/vnupam.4195.

38. Cục Thông tin Khoa học và Công nghệ Quốc gia. Tiềm năng phát triển năng lượng tái tạo ở Việt Nam, Hà Nội, Việt Nam, 2015. http://vista.gov.vn/vn-uploads/tong-luan/2015/t15_2015.pdf.

39. Phương, T. Nghiên cứu hiệu quả kinh tế của các giải pháp công nghệ giảm phát thải khí nhà kính trong xử lý chất thải rắn sinh hoạt ở thành phố Hà Nội, Luận án Tiến sỹ, Viện Khoa học Khí Tượng Thủy Văn và Biến đổi khí hậu, Hà Nội, Việt Nam, 2020. 


\title{
Current situation of greenhouse gas emissions in Vietnam: Opportunities and challenges
}

\author{
Nguyen Van Hieu ${ }^{*}$, Nguyen Hoang Nam ${ }^{2}$ \\ ${ }^{1}$ Capacity Development Center for Environment and Natural Resources (CEN); \\ hieunguyen@cen.org.vn \\ ${ }^{2}$ Institute of Strategy and Policy on Natural Resources and Environment (ISPONRE); \\ nguyenhoangnam275@gmail.com
}

\begin{abstract}
This paper evaluates the current situation and the forecast of GHG emissions in Vietnam for the period of 2000-2030 and analyses the insights of 5 main sectors including: energy, agriculture, industrial processes, waste and land use, land use change and forestry. The paper also sheds light on the opportunities and challenges in the field of GHG emission reduction. Accordingly, Vietnam has an advantage with plenty of "no-regret" measures, which have negative emission reduction costs but can result a total emission reduction of $4.9 \%$, which is more than half of the commitment level of $9 \%$ according to the updated NDC, while required up-front investment is 3.9 billion VND for the period of 2021-2030. The article also analyzes the five most prominent challenges today, especially emphasizing (i) Lack of specific plans and guidelines to reduce GHG emissions at the local level; and (ii) Lack of effective policies and mechanisms to mobilize the private sector for greenhouse gas mitigation. Accordingly, the article proposes the main focuses for Vietnam in the coming years.
\end{abstract}

Keywords: Greenhouse gas emissions; Mitigation; Opportunities; Challenges. 